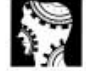

original papers letters in this report. Novel and successful approaches to dealing with copying clinical correspondence to patients should be reported so that clinical teams can adopt proven, suitable strategies. This should include methods of training and supervising inexperienced clinicians in what is expected of letters sent to service users and their carers.

\section{Declaration of interest}

None.

\section{References}

BOADEN, R. \& HARRIS, C. (2005) Copying letters to patients - will it happen? Family Practice, 22, 141-143.

CAPE, J., HARVEY, K., JOHNSON, S., et al (2005) Patients' views of letters their psychiatrists and psychologists send to referrers. Journal of Mental Health, 14 369-382.

COMBE, G., SHORT, C. \& STEPHENS, H. (2006) Copying letters to families: attitudes and experiences of child and adolescent psychiatrists. Psychiatric Bulletin, 30, 413-415.

DEPARTMENT OF HEALTH (2003) Copying Letters to Patients. Good Practice Guidelines. Department of Health. \& COUPE,T. (2005) Copying letters to patients: a study of patients' views. Psychiatric Bulletin, 29, $56-58$

NANDHRA, H., MURRAY, G., HYMAS, N., et al (2004) Medical records: doctors' and patients' experiences of copying letters to patients. Psychiatric Bulletin, 28, 40-42.

OKOLO, D. (2004) Copying letters to patients. Psychiatric Bulletin, 28, 343

ROYAL COLLEGE OF PSYCHIATRISTS (2004) Copying Clinical Letters to

Patients. Guidelines for Old Age

Psychiatrists. Royal College of

Psychiatrists Faculty for the Psychiatry of Old Age.

SAWHEY, I., TAJER, A. \& MORGAN, J. (2007) Copying clinical letters to patients - views of people with learning disabilities and their carers. British Journal of Developmental Disabilities, 53, 17-23.

SPIESSL, H., ROTHBAUER, J. \& CORDING, C. (2006) Discharge letters addressed to patients - confidence enhancement and psychoeducation
MARZANSKI, M., PADMAPRIYA, M.

(Entlassungsbriefe an Patienten Vertrauensbildende Maßnahme und Psychoedukation). PsychiatrischePraxis, 33, 296-298.

STURGE, C. (2004) Sharing information/disclosure. Psychiatric Bulletin, 28, 304.

SUBOTSKY, F. (2005) Copying letters to patients: issues for child and adolescent mental health services. Psychiatric Bulletin, 29, 201-203.

THAIR, T., BISSON, J. \& WILCOX, (2005) Copying clinic letters to psychiatric patients. Psychiatric Bulletin, 29, 327-329.

TRELOAR, A. \& ADAMIS, D. (2005) Sharing letters with patients and thei carers: problems and outcomes in elderly and dementia care. Psychiatric Bulletin, 29, 330-333.

UHER, R. \& TIMEHIN, C. (2006) Managing patient's information in a community mental health team. Psychiatric Bulletin, 30, 172-174. WALD, C., FAHY, M., WALKER, Z., et al (2003) What to tell dementia caregivers - the rule of threes International Journal of Geriatric Psychiatry, 18, 313-317.

*Julian Mason Specialist Registrar on Oxford Deanery Rotation in Psychiatry, West Oxfordshire Community Mental HealthTeam for OlderAdults, WelchWay, Witney, Oxfordshire 0X28 6JQ, email: jdtmason@msn.com, Daphne Rice Consultant in Old Age Psychiatry, Newbury Community Mental HealthTeam for Older Adults, Beechcroft, Berkshire

\title{
Valproate as prophylaxis for clozapine-induced seizures: survey of practice
}

\section{AIMS AND METHOD}

To evaluate the prescribing of valproate in clozapine-treated individuals who may be at risk of seizure. We collected point-prevalent clinical characteristics and demographics of all in-patients prescribed clozapine in an acute mental health trust. Data were collected from case notes, electronic records and drug charts, and analysed against a set audit standard.

\section{RESULTS}

Data were collected for 81 inpatients. Of all deemed to be at risk of seizure $(n=37)$ only $24 \%$ were prescribed valproate at a therapeutic plasma level.

\section{CLINICAL IMPLICATIONS}

The majority of patients prescribed clozapine at risk of seizures were not adequately protected from this risk. Clear guidelines are required.
Clozapine is an atypical antipsychotic agent with an established and valuable role in treatment-refractory schizophrenia (National Institute for Health and Clinical Excellence, 2002). In this patient group, clozapine has been shown to be consistently effective (Taylor \& Duncan-McConnell, 2000) and is more effective than switching to another atypical antipsychotic when other atypical agents have failed (McEvoy et al, 2006). However, it has a serious adverse effect profile and attrition from treatment is high (Ciapparelli et al, 2003). Outcome has been shown to be poor for individuals who discontinue clozapine for any reason and it has been observed that preventable death is a common occurrence in those stabilised on clozapine, including death associated with seizure (Atkinson et al, 2007).

Much has been written on clozapine's propensity for lowering the seizure threshold (Devinsky \& Pacia, 1994; Pacia \& Devinsky, 1994; Sajatovic \& Meltzer, 1996; 
Silvestri et al, 1998; Welch et al, 1994), including guidance for the management and prophylaxis of clozapine-related seizures (Devinsky \& Pacia, 1994; Taner et al, 1998; Welch et al, 1994). Recommendations include dose reduction, electroencephalogram (EEG), plasma-level monitoring and prophylactic valproate treatment.

The risk of seizure during clozapine treatment has been estimated at approximately $1 \%$ to $4.4 \%$ dependent on dose (Devinsky et al, 1991; Devinsky \& Pacia, 1994). However, seizures have been observed at all stages of treatment (Sajatovic \& Meltzer, 1996), at both high and low doses, and thus may not in fact be dose-dependent (Pacia \& Devinsky, 1994). They are perhaps more likely to be blood-level related (Greenwood-Smith et al, 2003) than dose-related and therefore more useful measures in assessing the risk of seizure may include EEG and plasma blood-level monitoring.

Although stringent licensing requirements demand tight control and monitoring for signs of clozapineinduced blood dyscrasias, little is known of monitoring in respect to other potential adverse effects of clozapine in clinical practice. Despite recommendations in the literature, clinical guidelines for preventing and managing seizures are not well established and practice may vary in the clinical setting (Welch et al, 1994). Management of such adverse effects is important and prophylactic treatment may enable the continued and valuable prescribing of clozapine in individuals who may be at risk of seizures despite therapeutic benefit (Taner et al, 1998).

An audit was carried out to evaluate the monitoring of clozapine plasma levels and the steps taken to reduce seizure risk in everyday clinical practice in a large mental health trust.

\section{Method}

In June 2007 this study was approved by the Drugs and Therapeutics Committee in South London and Maudsley National Health Service (NHS) Trust. All in-patients with a

Table 1. Demographic and clinical characteristics of patients in the study 1

\begin{tabular}{lc} 
Age, years & \\
Mean (s.d.) & $36.8(11.6)$ \\
Range & $12-64$ \\
Gender, $n$ (\%) & \\
$\quad$ Male & $27(70.4)$ \\
Female & $24(29.6)$ \\
Diagnosis, $n$ (\%) & $67(82.7)$ \\
Schizophrenia & $10(12.3)$ \\
Schizoaffective disorder & $2(2.5)$ \\
Bipolar affective disorder & $1(1.2)$ \\
Personality disorder & $1(1.2)$ \\
Early onset psychosis & $15.1(10.3)$ \\
Years of psychiatric illness, years ${ }^{2}$ & $1-47$ \\
Mean (s.d.) & \\
Range & \\
\hline 1. n=81. & \\
2. n=77.
\end{tabular}

current prescription for clozapine were identified and those with complete and accessible medical notes were included in the study sample. Medical notes (case notes, hospital computer records and drug charts) were located and the relevant information collected in relation to a set audit standard. Information recorded included patient demographics, current clozapine dose, reason for prescribing, plasma blood level, all other prescribed medication including dose and plasma level of valproate, and history of seizure or head injury.

The audit standard was set at: all in-patients prescribed clozapine with a plasma blood level more than $0.6 \mathrm{mg} / \mathrm{l}$ or a dose at or more than $600 \mathrm{mg} /$ day and/or co-prescribed additional epileptogenic drugs and/or with an existing seizure disorder, should be prescribed valproate at a dose sufficient to afford a therapeutic plasma level of $>50 \mathrm{mg} / \mathrm{l}$.

There were 81 in-patients with a current clozapine prescription who were included in the analysis. Their demographic and clinical characteristics are shown in Table 1. Data analysis was performed using SPSS 15.0 for Windows.

\section{Results}

\section{Medication}

Reason for clozapine prescription and dose and plasma levels of clozapine are shown in Table 2. Four in-patients were also prescribed venlafaxine, a significantly epileptogenic drug, and $32.1 \%$ of those prescribed clozapine were also prescribed an additional antipsychotic agent. The majority of co-prescription was augmentation with amisulpride $(n=19)$. Others included quetiapine, risperidone, aripiprazole and sulpiride. No other notable epileptogenic agents were prescribed in our sample. The only two anticonvulsant drugs prescribed in our sample were valproate $(n=33)$ at a mean dose of $1358 \mathrm{mg} /$ day and lamotrigine $(n=4)$. Most commonly individuals were prescribed valproate as a mood stabiliser (48.5\%) rather than for seizure prophylaxis (9.1\%). Alternative indications included clozapine augmentation and pre-existing epilepsy.

\section{'High-risk' individuals}

Of the 24 individuals with a clozapine level $>0.6 \mathrm{mg} /$ day or a dose of $>600 \mathrm{mg} /$ day ('high-clozapine group') 11 were also prescribed valproate $(45.8 \%$ of the highclozapine group).

Of the four individuals prescribed an additional epileptogenic drug, one also had a 'high' clozapine level or dose but none had a history of seizure disorder. Eleven of the total patients sample had a history of seizure or significant head injury recorded in the case notes. Of these, one patient also had a 'high' clozapine level. There were no individuals in this group also prescribed other epileptogenic drugs. original papers 
Table 2. Clozapine prescription

original papers treatment has been estimated at as high as $8 \%$ (Welch et al, 1994) and seizures have been shown to be a leading cause of death in those receiving clozapine (Atkinson et al, 2007). Even when not resulting in death, seizures occurring during clozapine treatment may result in its withdrawal with a notoriously poor outcome - increased bed stay, polypharmacy and a decline in global functioning have all been observed in the first year after cessation of clozapine prescription (Atkinson et al, 2007).

Despite the known risks, our results show that many clinicians involved in the care of those prescribed clozapine do not take steps to prevent seizure or to adequately measure or monitor its risk. More disturbing still was the observation that the most common reason for prescribing valproate in the 'at risk' sample was mood stabilisation and not seizure prophylaxis.

When considering the adverse effect profile of clozapine, much emphasis is placed on the drug's ability to cause blood dyscrasias and little on the risk of seizure. This may be attributed to the controls over regular blood monitoring which makes clinicians very aware of this possible adverse effect and often makes it their utmost concern when prescribing clozapine. It may also be that they are simply not aware of the risk of seizure or underestimate its magnitude. Alternatively, the risk may be well known but when considered against the likelihood of additional and enhanced adverse effects caused by a co-prescription of valproate, clinicians and patients may choose to avoid prophylactic medication in the light of a comparably smaller risk of seizures. It is also possible that clinicians, while aware of the risk, have little clear guidance on how best to manage it and therefore do not make appropriate treatment plans. Such guidance can be found in the Maudsley Prescribing Guidelines (Taylor et al, 2007) and, as the most widely used prescribing reference within the Trust and nationally, it raises the possibility that clinicians may be aware of the guidance in the literature but decide not to prescribe prophylactic valproate, perhaps based on the lack of good evidence that valproate actually prevents clozapine-induced seizures.

This study analysed all in-patients prescribed clozapine in a large urban mental health trust thus providing a complete sample of patients in a naturalistic setting. Despite the study's strengths, the sample size is small and the results reflect a point prevalence study of prescribing rather than a prospective study of outcome. The results are also representative of just one trust, and may not actually reflect practice elsewhere where local guidelines and experience may have a greater impact on prescribing. To our knowledge, there are currently no published data with which we can compare our results. Larger studies over different trusts would be useful in establishing current practice and to aid the development of much needed guidance in this critical area of clozapine management, in order to prevent harm and ultimately death in those prescribed clozapine.

\section{Declaration of interest}

Funding for this study was provided by Sanofi-Aventis in the form of an unrestricted grant. D.T. has received 
research funding, and consultancy and speaking fees from Sanofi-Aventis and Novartis.

\section{References}

ATKINSON, J. M., DOUGLAS-HALL, P., FISCHETTI, C., et al (2007) Outcome following clozapine discontinuation: a retrospective analysis. Journal of Clinical Psychiatry, 68, 1027-1030.

CIAPPARELLI, A., DELL'OSSO, L. BANDETTINI DI POGGIO, A., et al (2003) Clozapine in treatmentresistant patients with schizophrenia, schizoaffective disorder, or psychotic bipolar disorder: a naturalistic 48-month follow-up study. Journal of Clinical Psychiatry, 64 $451-458$.

DEVINSKY, O., HONIGFELD, G. \& PATIN, J. (1991) Clozapinerelated seizures. Neurology, $\mathbf{4 1}$ 369-371
DEVINSKY, O. \& PACIA, S.V. (1994) Seizures during clozapine therapy. Journal of Clinical Psychiatry, 55 (suppl B), 153-156

GREENWOOD-SMITHC, LUBMAN, D.I. \& CASTLE, D.J. (2003) Serum clozapine levels: a review of their clinical utility. Journal of Psychopharmacology, 17 234-238.

McEVOY, J. P., LIEBERMAN, J. A. SCOTT STROUP, T., et al (2006)

Effectiveness of clozapine versus olanzapine, quetiapine, and risperidone in patients with chronic schizophrenia who did not respond to prior atypical antipsychotic treatment. American Journal of Psychiatry, 163. $600-610$.
NATIONAL INSTITUTE FOR HEALTH AND CLINICAL EXCELLENCE (2002) Guidance on the use of newer (atypical) antipsychotic drugs for the treatmen of schizophrenia. HealthTechnology Appraisal No. 43. (http:// www.nice.org.uk/nicemedia/pdf/ ANTIPSYCHOTICfinalguidance.pdf).

PACIA, S.V. \& DEVINSKY, O. (1994)

Clozapine-related seizures: experience with 5629 patients. Neurology, 44, 2247-2249.

SAJATOVIC, M. \& MELTZER, H.Y. (1996) Clozapine-induced myoclonus and generalized seizures. Biological Psychiatry, 39, 367-370.

SILVESTRI, R. C., BROMFIELD, E. B. \& KHOSHBIN, S. (1998) Clozapineinduced seizures and EEG abnormalities in ambulatory psychiatric patients. Annals of Pharmacotherapy, 32, 1147-1151.

TANER, E., COSAR, B. \& ISIK, E. (1998) Clozapine-induced myoclonic seizures and valproic acid. International Journa of Psychiatry in Clinical Practice, 2, 53-55.

TAYLOR, D., PATON, C. \& KERWIN, R. (2007) The Maudsley Prescribing Guidelines (9th edn) Informa Healthcare.

TAYLOR, D. M. \& DUNCANMcCONNELL, D. (2000). Refractory schizophrenia and atypical

antipsychotics. Journal of Psychopharmacology, 14, 409-418

WELCH, J., MANSCHRECK, T. \& REDMOND, D. (1994) Clozapineinduced seizures and EEG changes. Journal of Neuropsychiatry and

Clinical Neurosciences, 6

Anna Sparshatt Senior Clinical Pharmacist, Eromona Whiskey Principal Clinical Pharmacist, * David Taylor Chief Pharmacist, Maudsley Hospital, Denmark Hill, London SE5 8AZ, email: David.Taylor@slam.nhs.uk

\section{Referral patterns and acetylcholinesterase inhibitor prescribing for cognitive impairment (1999-2007): impact of NICE guidelines}

\section{AIMS AND METHOD}

We hypothesised that the proportion of people referred to two outer London mental healthcare services for older people with cognitive impairment increased after the 2001 National Institute for Health and Clinical Excellence (NICE) guidelines for acetylcholinesterase (AChE) inhibitor use in Alzheimer's disease, but declined after the amended 2006 guidelines. We reviewed case notes for 546 individuals referred between 1999 and 2007.

RESULTS

The proportion of individuals with cognitive impairment referred increased between 1999 (56.1\%) and 2005 $\left(70.5 \%, \chi^{2}=5.4, P=0.02\right)$, as did the proportion prescribed $A C h E$ inhibitor
(0.8\% to $\left.16.1 \%, \gamma^{2}=27.5, P<0.001\right)$. There were no significant changes between 2005 and 2007.

\section{CLINICAL IMPLICATIONS}

The 2006 NICE amendment may have curbed the increase in psychiatric referrals and $\mathrm{AChE}$ inhibitor prescribing rates for people with cognitive impairment but so far these rates have not decreased.
In 2001, the National Institute for Health and Clinical Excellence (NICE) recommended the use of donepezil, galantamine and rivastigmine for people with Alzheimer's disease of mild and moderate severity, with a Mini Mental State Examination (MMSE) score above 12 (National Institute for Health and Clinical Excellence, 2001). These guidelines, together with other initiatives, were reported to have led to an increase in referrals to psychiatric services for cognitive impairment, which appeared to be caused by an increase in the number of people with mild impairment who were referred (O'Loughlin \& Darley, 2006). In November 2006, NICE revised their recommendations, indicating that prescription of acetylcholinesterase (AChE) inhibitors should be restricted to people with moderate Alzheimer's disease for reasons of costbenefit (National Institute for Health and Clinical
Excellence, 2006). A High Court challenge to this amendment in 2007 was unsuccessful.

This study is the first, to our knowledge, to explore the impact of the 2006 revised guidelines, and the considerable publicity surrounding them, on the rate of referral to psychiatric services of people with cognitive impairment and the proportion prescribed AChE inhibitors. It is possible that the revised guidance may have led to old age psychiatrists prescribing fewer AChE inhibitors, especially among people with mild dementia, and deterred general practitioners (GPs) from referring to mental health services people with mild cognitive impairment, if receipt of an AChE inhibitor had been an important reason for referral. We hypothesised that the proportion of people referred to two older people's community mental health services who had cognitive 